\title{
AS POLÍTICAS DE ABATE SOCIAL NO BRASIL CONTEMPORÂNEO
}

\author{
Amélia Cohn \\ Docente do Programa de Pós-Graduação em Direito da Saúde \\ da Universidade Santa Cecília.E-mail: cohn.amel@gmail.com
}

Orcid: 0000-0002-2416-2624

http://dx.doi.org/10.1590/0102-129160/109

O cotidiano dos meios de comunicação e das redes faz com que passemos da perplexidade ao riso da indiferença como arma de proteção diante do descalabro atual da situação política do país. O pudor e a delicadeza impedem as citações das declarações escatológicas do atual mandatário (Jair Messias Bolsonaro). No entanto, o compromisso analítico para buscar entender a realidade atual demanda que se destaquem algumas delas, dentre as não escatológicas, por serem altamente esclarecedoras:

Os caras vão morrer na rua igual barata, pô. E tem que ser assim. (Maia, 2019)

Ideologia de gênero é coisa do capeta. (Ideologia..., 2019)

Sou o capitão motosserra. (Barbosa, 2019)

Todo mundo gostaria de passar a tarde com um príncipe.

Principalmente vocês, mulheres. (Senra, 2019) 
Quilombola não serve nem para procriar. (Bolsonaro..., 2017)

Enquanto eu for presidente, não tem demarcação de terra indígena. (Putti, 2019)

Esse cardápio, frugal diante da extensão de possibilidades de escolha apresentadas, demonstra que os direitos fundamentais e sociais dos cidadãos no país estão na mira de um ataque mortal, abarcando a gama das diversidades das situações sociais e suas distintas identidades. Não basta atualmente distinguir entre pobres e não pobres, pois os crivos sociais da diversidade constituem os alvos do combate ao que não for considerado de forma estrita pelo segmento dos mandatários atuais como "normalidade" social. A questão para análise que se apresenta como desafio é buscar delinear a natureza dessa avalanche destrutiva das conquistas sociais do país, a partir de 2019, que sucede um período 130 da jovem democracia brasileira em que a concretização dos direitos dos cidadãos contemplados na Constituição de 1988 avançou de forma significativa, sobretudo a partir de 1995 (governos Fernando Henrique Cardoso), e mais acentuadamente a partir de 2003 (governos Luiz Inácio Lula da Silva e Dilma Rousseff). O que foge à normalidade imperativa dos governantes coincide, em sua maioria, com os segmentos pobres e negros da sociedade, bem como com os grupos LGBTQI+, quilombolas e indígenas, que "se atrevem" a estarem assentados em terras ricas em minério e florestas, e que ousam, tais como aqueles, contar com o direito constitucional às suas terras.

A partir de 2016, após o impedimento de Dilma Rousseff, acirrou-se a disputa entre dois projetos opostos, configurada pela radicalidade do projeto neoliberal que a nova ordem representa a partir de então, em contraponto às propostas socialdemocratas, em suas várias versões, em vigência desde 1995. A presença na agenda pública desses dois 
projetos em disputa na atual conjuntura pressuporia um ambiente democrático em que essas distintas narrativas deveriam competir, observadas as regras da reciprocidade de reconhecimento de sua legitimidade. No entanto, o ambiente atual caracteriza-se por contextualizar a morte "branca" da ordem democrática, o não reconhecimento do contraditório; o não funcionamento legítimo das instituições democráticas, apesar de sua formal legalidade, em muitos dos casos. De fato, a questão que se coloca é como enfrentar o tema da justiça social e das políticas públicas de corte social (em particular) quando a gestão do social caracteriza-se por um forte traço segregacionista, excludente, com laivos explícitos de natureza fascista?

Diante da catástrofe atual, torna-se imperativo buscar as contradições enraizadas no passado que permitam esclarecer o retrocesso que se vive hoje na área social com o intuito de vislumbrar possibilidades propositivas nesta conjuntura tão desfavorável. Em outras palavras, de se redefinir as linhas do horizonte, vale dizer da utopia, para que ela cumpra sua função, a de nos fazer caminhar, tal como Fernando Birri, o diretor de cinema, a define, numa entrevista concedida juntamente com Eduardo Galeano, que a difundiu (Labaque, 2016, p. 16).

\section{Principais traços das políticas sociais até 1988}

A nova ordem ditada pela Constituição de 1988 é forjada no seio de um perfil de rede de proteção social constituída ao longo daquele século que tem como característica ser composta por um conjunto de políticas sociais fragmentadas entre si, com seus ritmos e trajetórias específicos traçados sem sincronismo, contando com fontes distintas de financiamento sem garantias constitucionais, e não configurando o acesso a serviços e benefícios sociais como direitos. $\mathrm{O}$ acesso a estes era determinado pelo acesso ao mercado, em particular ao mercado de trabalho do setor privado, via previdência social e o mecanismo de contribuição compulsória. 
Assim, pode-se distinguir o acesso a esses serviços e benefícios entre aqueles contributivos (previdência social, sob a forma de seguro social), assistencialistas (filantropia) e os que se configuravam como dádiva, num complexo jogo entre reciprocidade, indiferença e piedade (Caillé, 2014, 42-59).

A herança do século passado é a de que as formas de regulação social forjadas por meio de políticas sociais, apesar de sua diversidade, tinham como sentido essencial dar suporte ao mercado produtor desses serviços, e operador desses benefícios. No primeiro caso, por meio da compra de serviços privados para satisfação da demanda criada pela Estado (exemplo, direito à assistência médica previdenciária por parte dos trabalhadores assalariados urbanos); no segundo caso, fomentando o mercado e a circulação de mercadorias via aumento da capacidade de consumo desses trabalhadores quando não mais aptos para o trabalho. Foi dessa forma que o setor da saúde, no país, foi privatizado 132 muito precocemente, a partir das Caixas de Aposentadorias e Pensões (CAPs), em 1923, até o Instituto Nacional de Assistência Médica Previdenciária (Inamps), criado em 1977 e extinto em 1993, período em que se constituiu um dos setores privados mais robustos da economia nacional e dentre os setores privados de saúde latino americanos. Já no caso da educação, a privatização do setor passa a ocorrer de forma acentuada a partir do golpe civil-militar de 1964.

Assim, independentemente dos regimes políticos e dos modelos de desenvolvimento econômico adotados durante o século XX, na área social evidencia-se como variável permanente a concepção do social como produto virtuoso do projeto desenvolvimentista (em suas várias acepções) assumido numa sociedade fundada no trabalho formal. Daí decorrem duas consequências imediatas e estruturais na área social: os direitos sociais, concebidos essencialmente como direito ao acesso a benefícios e ao consumo de serviços sociais, e regulados pela condição dos indivíduos no mercado de 
trabalho, regulado ele também pelo Estado. A reconhecida cidadania regulada, tal como analisada e formulada em estudo pioneiro de Wanderley Guilherme dos Santos (Santos, 1979); e com isso, no pós-1988, a dificuldade de se dissociar, no imaginário social, a condição de indivíduos portadores de direitos cidadãos da sua condição de mercado. Esse crivo do mercado ocorre na disponibilidade da oferta e do acesso aos serviços sociais, tanto em termos da fragmentação da sua oferta quanto da segmentação da clientela e dos usuários, em todos os setores das políticas sociais. Eis um traço de raiz da rede de proteção social brasileira que persiste até mais de 30 anos após a promulgação da Constituição brasileira. O que se traduz num quadro que Ferreira de Souza traça ao longo do século como um traço de nossa história marcado pela "determinação institucional da desigualdade e de seu caráter inercial" (Ferreira de Souza, 2018, p. 284). E que se expressa no que Medeiros (Medeiros, 2016, p. 176) denomina de "políticas de igualdade por inclusão", que reconhecem direitos de uma parte da população buscando recuperar o atraso relativo dos demais, sem contudo afetar a pirâmide da concentração de renda.

A questão da pobreza e das desigualdades sociais naturalizadas, quando não revestidas dos preconceitos inerentes a uma sociedade de origens escravocratas, segue concebida como própria de nossa "natureza" social, numa ordem em que cada segmento social deve ocupar seu lugar específico, constituindo as exceções fenômenos da "meritocracia". Esta, por sua vez, enraizada nas diferenças estabelecidas pelo mercado e reafirmadas pelo sistema de proteção social brasileiro, altamente diferenciador das "castas" de trabalhadores, inter e intra categorias, sejam eles do setor público ou privado. Revestindo-se a previdência social enquanto seguro social como eixo central da montagem da rede de proteção social no país, as demais políticas setoriais giram em torno dela como uma constelação desequilibrada, 
cada uma tendo suas prioridades e implementação definidas de forma autônoma, sem sincronia. Daí resultam duas características básicas que a nova ordem constitucional herda ao mesmo tempo que proclama e alça a satisfação das necessidades básicas dos indivíduos como direitos sociais: os direitos historicamente conquistados no decorrer do século XX, ao contrário do que ocorre na construção dos Estados de Bem-Estar Social, aqui espelham as diferenças e desigualdades geradas pelo mercado, quando muito configurando uma proteção social de caráter distributivo intergeracional. E a outra, a da privatização precoce e facilmente absorvida das instituições prestadoras de serviços, que passam a ter no Estado a fonte segura para sua demanda. Daí a consolidação da representação social dos direitos sociais enquanto privilégios, exatamente porque altamente diferenciados, advindos de lutas de corporações dos trabalhadores, dos setores público e privado.

134 Nessa experiência histórica de construção do sistema de proteção social não há lugar para a questão da pobreza, relegada à filantropia privada, ou à iniciativa da esfera privada individual sob a forma de dádiva; a pobreza é naturalizada, e a desigualdade social ignorada. Isto porque a questão social, se na época da República Velha consistia numa questão de polícia, no período pós varguista consistia numa questão de industrialização e construção de um Estado nacional, com um padrão de regulação social estrito associado à repressão política; e no período desenvolvimentista à solução via um projeto econômico que visava levar o mercado, e com isso a inclusão social via emprego, a todo o território nacional. O projeto econômico, assim, sempre prevaleceu sobre qualquer projeto social, tornando-os mesmo incompatíveis entre si enquanto concepção, uma vez que o próprio desenvolvimento econômico, acreditava-se, levava ao desenvolvimento social, subproduto daquele. Oportuno resgatar Jessé Souza: 
Tudo acontece como se esses indivíduos [os brasileiros, independentemente de sua classe ou pertencimento social] essencialmente semelhantes apenas diferissem na renda que ganham e que o progresso econômico seria, portanto, o Deus ex machina ao qual caberia resolver problemas como desigualdade, marginalização e subcidadania. Existe entre nós uma crença "fetichista" no progresso econômico, que faz esperar da expansão do mercado a resolução de todos os nossos problemas sociais. (Souza, 2003, p. 51)

Interessante notar que, em decorrência, a área social até então jamais foi concebida enquanto um setor da economia que gera capital e desenvolvimento tecnológico, e que, portanto, pode se tornar estratégico para o próprio desenvolvimento econômico. Isto mesmo quando, por exemplo, via Inamps, a produção de serviços de assistência médica pelo setor privado, e os inputs e outputs que então já gerava, tornou-se a partir de meados da década de 1970 o principal prestador de serviços para a população previdenciária, portanto, para os trabalhadores urbanos do setor privado da economia e seus dependentes. Talvez o caso mais expressivo dessa submissão do social ao econômico seja o Plano de Metas do governo Juscelino Kubitschek (1956-1961), que das 31 metas somente uma era destinada à área social, a educação, voltada à qualificação da mão de obra demandada pelo projeto de desenvolver o país num ritmo de "50 anos em 5". E foi com ele que se esgotou o modelo de desenvolvimento via substituição de importações.

Esse período desenvolvimentista deixa como legado uma rede de proteção social capitaneada pela previdência social enquanto mecanismo de extensão de direitos sociais de natureza contributiva, e que atendeu a duas frentes de articulação com as propostas de desenvolvimento econômico: a previdência social como mecanismo de captação da poupança individual dos trabalhadores assalariados urbanos 
via regime de capitalização pelo Estado que destinava esses recursos para investimentos públicos na área de infraestrutura (na década de 1950 a Petrobrás e a construção de Brasília no período Kubitschek, por exemplo); e a ação do Estado como impulsionador do setor privado de produção de serviços sociais, e com isso um padrão de acumulação privada na área social que não obedece às leis estritas da concorrência do mercado, exatamente por ter sua demanda garantida pela ação pública.

Outra característica herdada na área social é a tradição de políticas altamente centralizadas e hierarquizadas entre as esferas federadas, cabendo aos estados e municípios pouca autonomia na definição das prioridades na área social e sua grande dependência de recursos e das prioridades definidas na esfera federal. Os programas e as políticas sociais, à época, desconheciam o exercício do controle público (comumente denominado de controle social pela literatura especializada 136 hoje corrente), expressando-se as demandas sociais por meio de partidos políticos, organizações sindicais e alguns movimentos sociais externos aos espaços institucionais então existentes. Talvez seja o caso de se lembrar, na década de 1950, das Ligas Camponesas, por exemplo.

O golpe civil-militar de 1964 radicaliza aqueles traços da rede de proteção social brasileira que vinham sendo consolidados: por meio de mecanismos específicos de financiamento, dentre eles a partir do início de 1974 pelo Conselho de Desenvolvimento Econômico e pelo Conselho de Desenvolvimento Social criados pelo governo do Gal. Ernesto Geisel (Cordato, 1996), componentes de uma reforma administrativa visando "modernizar" o Estado. E ao mesmo tempo que se acentua a privatização da área social sustentada pelo Estado via políticas sociais paradoxalmente ampliam-se, num regime ditatorial, direitos sociais, sobretudo via previdência social, como a extensão da cobertura para os trabalhadores rurais, a partir de 1972 (embora 
o Estatuto do Trabalhador Rural date de 1962), e para os empregados domésticos. Estes fatos ressaltam um traço paradoxal da história do país na área social: até 1988 uma extensão expressiva dos direitos sociais deu-se em regimes ditatoriais ou acentuadamente autoritários, em que as políticas sociais atuavam essencialmente como forma de captação de recursos da poupança individual privada e compulsória dos assalariados e como mecanismo de regulação social, no sentido de sua normatização, mais do que como mecanismo de legitimação do poder, uma vez que este se dava pela força. Os períodos de governo de Getúlio Vargas são expressivos, embora seja necessário reconhecer que a extensão dos direitos sociais na década de 1970 tenha ocorrido num período que se caracterizava pelo início da busca de uma distensão "gradual, lenta e segura" para uma ordem democrática.

A ebulição social dos anos de 1970 no país foi marcada pela mobilização dos operários, dos movimentos sociais congregando distintos atores sociais para além das classes assalariadas urbanas e rurais, tendo como eixo das reivindicações a restauração de uma ordem democrática e a conquista de direitos civis, políticos e sociais. Na inúmera gama de estudos a respeito da transição democrática brasileira a partir da década de 1970, sobretudo a partir de 1975, a unanimidade gira em torno do fato de que se tratou de uma transição sem ruptura com o ordenamento social anterior, o que por sua vez tem como consequência o fato de que esse processo redundou na imposição de limites estreitos à nova ordem que então se gestava.

O regime democratizante instituído após o fim da ditadura militar deu-se num pacto também conhecido como "transição transada”. Foram suas condições de veto às eleições gerais diretas em 1984 e a eleição presidencial da chapa TancredoSarney, em 1985, pela via indireta do espúrio colégio eleitoral, sob controle das forças oligárquicas e monitorado 
pela cúpula do regime da farda, que se retirava da cena, mas não se rendia. (Hardman, 2019, p. 121)

No que importa aqui resta ressalvar que a luta por novos direitos vinha atrelada ao que Sergio Arouca, um dos líderes do movimento sanitário que se inicia em 1975, denominava como "luta por um projeto civilizatório": a reconquista das liberdades políticas concebida como estreitamente associada à conquista de novos direitos sociais, entendidos como direitos fundamentais, e que foram no final da década seguinte contemplados na nova ordem constitucional, com destaque para o arcabouço do sistema de seguridade social, do qual constam saúde e assistência social, para além da previdência social.

A transição democrática, na área social caracteriza-se na sua essência pela luta pela democratização do Estado e da sociedade, amalgamada por uma dinâmica social congregando distintos setores sociais e instituições como a Igreja 138 católica progressista de então, mas ao mesmo tempo marcada pelas características do brasileiro como "homem cordial", com suas origens numa ordem escravocrata, como, dentre outros, acentua Jessé Souza (Souza, 2017). Assim, reafirma-se a tendência histórica no país de a pobreza ser em maior ou menor grau reconhecida como objeto de atenção dos distintos governos desse período, embora novamente jamais a desigualdade social, em grande medida não só pelas características de nossas elites, mas pelo seu horror a rupturas. Na transição democrática não seria distinto: a disputa entre os antigos privilégios que reagem às mudanças acirra os conflitos sociais e possibilitam a emergência de novas reivindicações sociais, compondo um leque altamente diferenciado dessas demandas, mas que no seu conjunto redundam numa combinação de políticas distributivas e de regulação que sustentam o desenvolvimento do país mas que pouco impactam o grau de desigualdade social. É como Alston et al. (2013) analisam a transição democrática: no 
"ocaso do desenvolvimentismo da ditadura" um momento de mudança de seu contrato social, e a Constituição de 1988 expressando a cristalização desse novo contrato, tendo como característica central a priorização da inclusão social. No entanto, o amálgama desse conjunto diferenciado de demandas sociais em disputa era favorecido pela luta pela redemocratização do país e pela construção de um Estado e de uma sociedade democrática, o que foi possível graças aos limites impostos ou previamente auto definidos dessas mesmas demandas, em grande medida recaindo desproporcionalmente sobre uma tímida dimensão distributiva das demandas sociais, e portanto junto às ações do Estado na área social, em detrimento da sua dimensão redistributiva.

A "Constituição Cidadã" consolida sob a forma da lei a expressão das demandas sociais então em curso, tanto no que diz respeito à organização do Estado e das instituições políticas, como ao reconhecimento de direitos sociais até então inéditos no país. Ela é expressão da luta pela democratização do país enquanto uma luta contra o Estado militar, autoritário e violento, e a favor da reconquista das instituições próprias da ordem democrática. Os direitos sociais são instituídos como direitos fundamentais pétreos. É instituída a forma de gestão participativa e democrática, e afirmado o fortalecimento, na área social, da racionalidade e responsabilidade públicas (estatais) frente às privadas. Emerge o Estado como provedor dos direitos sociais, e ao mesmo tempo como produtor e regulador dos serviços correspondentes. Necessário ressaltar, no entanto, que essas conquistas na área social advêm de uma mobilização social para além das mobilizações sociais setoriais de cada segmento da área social; elas eram amalgamadas pela luta pela redemocratização do país, extrapolando portanto seus limites específicos enquanto demandas setoriais.

A partir de então as conquistas sociais reconhecidas na Constituição de 1988 começam a ser implementadas, 
instituições estatais e públicas a ser criadas, e nas décadas de 1990 e de 2000 ocorrem avanços significativos na nova formatação da rede de proteção social no país. Em primeiro lugar, porque o novo marco dos direitos sociais é fundado na concepção de seguridade social, tal como nos países centrais, alçando saúde e assistência social para a matriz dos direitos sociais, financiados com fontes diversificadas de recursos. E em que pese Collor de Melo (1990-1992) ter vetado a repartição de recursos entre os três componentes da seguridade social, tal como previsto na Constituição, e com isso esquartejado a seguridade social em termos de transferências (e garantia) de fontes de financiamento, foi dada prioridade à área social nos diferentes governos que se sucederam; as políticas públicas agora na qualidade de se traduzirem na implementação dos direitos constitucionais recém instituídos.

Nos governos Fernando Henrique Cardoso (1995-2002) 140 destacam-se o Programa Comunidade Solidária (19952002), com prioridade para a população mais vulnerável, e os programas de transferência de renda com concessão de bolsas e auxílios segmentados por área social - Bolsa Escola, Bolsa Alimentação, Auxílio Gás, cada um contando com seu cadastro próprio de beneficiários, sem compatibilidade técnica de diálogo entre eles. Na realidade, essa segmentação setorial possibilitava que o presidente contemplasse politicamente seus principais candidatos à sucessão. Na área da educação houve avanços, contrapostos a ações no sentido da privatização da educação básica - infantil, fundamental e médio; e ausência de prioridade para o ensino superior. Na área da saúde, para além dos avanços na implementação do SUS (sustentada desde o início da Reforma Sanitária por profissionais e especialistas da saúde vinculados ao movimento e ocupando postos no interior da administração federal), sempre numa relação tensa e contraditória com os interesses privados aí presentes, destacam-se a introdução 
dos medicamentos genéricos, em 1999, que mais em tese do que na prática levariam a uma queda expressiva dos preços; e a instituição da distribuição gratuita, pela rede pública, da terapia tripla (o "coquetel") para HIV/Aids (1996).

No entanto não resta dúvida que, em que pesem as limitações impostas pela opção de ajuste econômico com vistas ao equilibro do déficit fiscal exigido pelas agências multilaterais, nessas gestões verifica-se uma diversidade de áreas de atuação no âmbito social - somente o Programa Comunidade Solidária conta com 16 programas setoriais. Além da diversidade, e apesar de também ter havido políticas nas áreas da agricultura familiar e de geração de emprego e qualificação do trabalhador, um balanço do conjunto da ação social desse período revela, no entanto, ter sido ele pouco ousado, senão mesmo tímido e convencional (Cohn, 1999).

Nos governos Lula da Silva (2003-2010) o investimento econômico e político na área social radicaliza-se, se comparado ao período anterior. Mas igualmente não perde o traço de ser distributivo e não redistributivo, embora mais nuançada sua dependência dos limites impostos pela supremacia do econômico, em que pese ainda se dar num contexto de ajuste. Um dos primeiros atos, após sua posse, foi instituir o Programa Fome Zero, já no início de 2003, e que vinha responder a um dos eixos centrais de sua campanha eleitoral. Vigente durante o primeiro ano de seu governo, abrigado num ministério criado especificamente para ele, o Ministério Extraordinário de Segurança Alimentar e Combate à Fome (Mesa), instituiu o Cartão Alimentação, agora vinculado à aquisição de alimentos, sob exigência de comprovação. Em outubro daquele ano é criado o Programa Bolsa Família (PBF), por Medida Provisória transformada em lei em janeiro de 2004, quando também é criado o Ministério do Desenvolvimento Social e Combate à Fome (MDS). A partir de então o Fome Zero é extinto, torna-se uma secretaria no 
interior do novo ministério, que também agrega o PBF e a assistência social, estes também sob responsabilidade de secretarias específicas. A partir de então o PBF assume lugar de destaque no conjunto das políticas sociais, expande-se de forma acelerada, e transforma-se numa experiência exemplar em termos internacionais. A novidade que o PBF traz na área das políticas sociais no país reside no fato de, para além de sua capilaridade social, que então confluía com a capilaridade social dos programas que vinham sendo implementados na área da saúde no nível da atenção primária da saúde, a transferência dos recursos aos beneficiários se dar diretamente a eles, sem a intermediação do poder local. Um segundo traço do programa consiste nas condicionalidades: a exigência do cumprimento de compromissos por parte dos beneficiários nas áreas da educação e da saúde, herança dos programas de bolsas advindos da era FHC, e acolhidos pela nova equipe de governo.

142 A par esses programas, inúmeros outros foram incrementados, ou mesmo implantados, dentre eles: construção de cisternas, habitação popular, assentamentos rurais, agricultura familiar, economia solidária, demarcação de terras indígenas, aqueles voltados à inclusão no sistema educacional com a criação do Fundo de Manutenção e Desenvolvimento da Educação Básica e de Valorização dos Profissionais da Educação (Fundeb) em 2007, que expira no final de 2020, e que veio a substituir o Fundo de Manutenção e Desenvolvimento Do Ensino Fundamental e de Valorização do Magistério (Fundef) - 1998-2006; a criação de bolsas e a valorização do Exame Nacional do Ensino Médio (Enem), criado em 1998, para acesso ao Sistema de Seleção Unificada (Sisu), o Programa Universidade para Todos (Prouni), e o Fundo de Financiamento Estudantil (Fies) enquanto mecanismos de ampliação do acesso ao ensino superior por meio de concessão de bolsas ou de financiamento, agora tendo incrementados seus recursos 
financeiros. E, fundamental, a política econômica de consistente aumento real do salário-mínimo, reconhecidamente um dos mecanismos mais eficazes de distribuição da renda e combate à desigualdade social porque traz consigo amplos segmentos sociais vinculados aos direitos previdenciários e Benefício de Prestação Continuada (BPC), que tem o valor do benefício indexado pelo salário-mínimo. Já em 2005 o salário-mínimo aumenta para o dobro do ano anterior, e em 2010 o aumento acumulado desde aquela data era da ordem de 50\% (Barbosa e Pereira, 2010). Nesse período, as políticas de renda para a base da pirâmide, via salário-mínimo, previdência social, assistência social e programa de transferência de renda permitiram que o incremento da renda da base da pirâmide fosse significativamente maior do que o do ápice da pirâmide, o que permitiu uma mobilidade social ascendente, que por sua vez auxiliou no crescimento da economia, sustentada também pelas commodities, mas internamente pelo incremento do consumo.

Necessário frisar, no entanto, algumas características do conjunto da atuação na área social desse período pós-constituição até 2016, quando do golpe burocrático-parlamentar (Santos, 2017, p. 8). Com nuances distintas, não poucas vezes radicalmente distintas, o que não importa para a linha de raciocínio aqui, os avanços na área social continuaram tendo sua definição regida pela lógica da primazia do econômico sobre o social, continuando este concebido na sua essência como um subproduto daquele. Mas os avanços foram significativos. Tomando como exemplo o Sistema Único de Saúde (SUS), reconhecido internacionalmente como o maior sistema público de saúde, seu desenvolvimento ocorre num contexto de permanente subfinanciamento do setor, mesmo que atualmente a saúde seja finalmente reconhecida também como um setor econômico que gera riqueza e acumulação de capital. De qualquer forma, a expansão da cobertura dos serviços sociais via políticas e programas 
sociais deu-se de forma expressiva, sobretudo mais acentuadamente nos governos Lula e Dilma (2011-2016). De fato, no caso da saúde a cobertura dos serviços de saúde expandiu-se e espraiou-se pelo território nacional, o que não se traduz, necessariamente, em expansão do acesso aos serviços sociais. Estes são dependentes de outros fatores, que abarcam desde capacitação dos gestores públicos até investimento em infraestrutura dos equipamentos públicos e financiamento adequado.

Não obstante, um traço inovador das políticas sociais foi desenhado, e consiste ele na sua capilaridade social e territorial. Não só os equipamentos sociais transpõem os limites físicos e operacionais de seus muros, como equipamentos novos são instalados nos rincões do país, a partir de 2005 com o suporte do Sistema Único de Assistência Social (Suas), criado em 2005. Na área da saúde, o exemplo é o Programa Mais Médicos (PMM), criado em 2013 e que 144 sofreu um golpe mortal em 2018, com a retirada dos médicos cubanos diante da diplomacia desairosa com que foram tratados o governo cubano e a Organização Panamericana de Saúde, instituição internacional vinculada aos organismos internacionais da Organização das Nações Unidas (ONU) e a Organização Mundial da Saúde (OMS), e que intermediava e operava o acordo entre os dois países.

Da mesma forma, ocorreram avanços no processo de descentralização das políticas sociais, porém sempre de forma ambígua e contraditória. Definitivamente este é um país das não rupturas. A descentralização, embora reconhecida a autonomia dos municípios para a definição de suas políticas sociais obedecendo aos marcos constitucionais, não contou na área social com a definições precisas das responsabilidades de cada esfera de governo, muito menos com recursos financeiros que possibilitassem sustentar no nível local as demandas por serviços que acabam recaindo sobre ele, na ausência de serviços estaduais e federais, que, 
como herança histórica, concentram-se nos grandes núcleos urbanos - centros de poder político e/ou econômico. O desafio de descentralizar a infraestrutura dos serviços sociais ainda persiste, uma vez que é dependente de investimentos em equipamentos, capacidade de gestão, alocação e permanência dos profissionais no nível local, dentre outros. A tendência, assim, foi ocorrer uma "descentralização concentrada", vale dizer, ainda determinada em grande medida pelos repasses dos recursos federais para estados e particularmente para os municípios, em que pesem os Fundos de Participação municipais e estaduais instituídos a partir de 1988. "Descentralização concentrada" também na medida em que a expansão da cobertura de serviços sociais que ocorre no país desde então, sobretudo a partir de 2002, não vem estreitamente articulada à cobertura do acesso efetivo da população aos serviços ofertados pelos equipamentos, sobretudo dos segmentos de mais baixa renda. "Já estou de canela seca de ir atrás", sertaneja do interior da Paraíba em busca do acesso ao benefício do PBF (Cohn, 2012, p. 33).

Quanto às formas de gestão participativa nas políticas sociais, elas ganham importância, o que se traduz na emergência de novos sujeitos sociais representantes de segmentos sociais com interesses particulares que se tornam presentes nos colegiados de gestão, previstos em lei, como por exemplo os conselhos nacionais, estaduais e municipais de saúde, educação e assistência social (nem todos de caráter deliberativo), e em conselhos gestores de serviços específicos dos governos estaduais e locais, a depender do perfil. Vale o registro de que a participação social, defendida na transição democrática como mecanismo para se imprimir maior racionalidade à gestão pública com relação ao perfil das necessidades da sociedade e possibilitar maior permeabilidade do Estado à prática democrática, na diversidade das experiências pelo país revelou-se com temerária frequência como instrumento de legitimação das políticas 
governamentais praticadas, muito embora tenha representado um avanço na diversidade da agenda pública de demandas até então invisíveis para o Estado. Registre-se que a primeira experiência de participação social data de 1989, com o Orçamento Participativo em Porto Alegre (Olívio Dutra 1989-1993) (Avritzer, 2002), e que não ocorria no interior dos espaços institucionais de participação social definidos pela Constituição de 1988.

No entanto, Restrepo, ao se debruçar sobre a experiência de descentralização e de participação social colombiana utiliza o conceito de participação tutelada referindo-se à experiência que as associa dada a presença de um fenômeno de ordem estrutural, e que diz respeito à internacionalização da economia, que demanda das economias periféricas políticas de ajuste incompatíveis com a expansão e crescente articulação de movimentos cívicos e suas demandas sociais.

O conceito vale também para o caso brasileiro, em que 146 pese a participação social na gestão da coisa pública, no calor das conquistas sociais por ocasião da Assembleia Nacional Constituinte, e posteriormente no calor dos desafios para a implementação das diretrizes e princípios que regem a área social agora determinada como respondendo a direitos sociais, tenha representado um vigoroso avanço em termos da democratização da sociedade. Emergiram no cenário público novos sujeitos sociais na qualidade de cidadãos portadores de direitos e de demandas legítimas junto à esfera política, embora ela não tenha sido suficientemente vigorosa para infletir os traços clientelista, autoritário e assistencialista do conteúdo social das políticas sociais. Modelo histórico de dominação do Estado brasileiro, um traço fundante da sua prática social e política, abrangendo dos governantes aos gestores dos serviços, programas e políticas sociais.

No entanto, em que pesem os desafios de se buscar uma nova ordem e obedecer novas diretrizes na implementação das políticas sociais, a partir de 1988 até muito recentemente 
verifica-se um fortalecimento do setor público estatal na área social, embora sempre em confronto com os interesses do setor privado produtor de serviços sociais. Basta afirmar que, na atualidade, o setor privado da saúde revela-se o mais robusto economicamente e o mais sofisticado nas formas de articulação de distintas modalidades de arranjos internos do setor privado (lucrativo e não lucrativo) da América Latina. A referência ao setor público como "público estatal” não é casual. O ideário dos militantes da área social, a partir de meados da década de 1970, associando direitos sociais (mesmo que pensados e mobilizados de forma segmentada) com a democratização do Estado, confundia o público com o estatal, e só posteriormente, a partir da segunda metade dos anos 1990 é que se assume que segmentos da produção privada do setor da área social podem se articular com o segmento estatal sob a lógica da racionalidade pública da gestão. A outra face da moeda é que o Estado, a partir de então, passa a se tornar, concomitantemente, o provedor dos direitos sociais, o responsável pela sua oferta (produção, de forma direta ou indireta), e ao mesmo tempo regulador dos serviços, num acúmulo de funções que embaralham fronteiras de funções e tendem a se mesclar nas ações de responsabilidade do Estado, pois é o mesmo agente que as exerce.

Assim, a partir de 2003 assiste-se a um período de políticas agressivas de inclusão social, e a questão da pobreza vem agora associada à questão da desigualdade social, sempre tão evitada na agenda pública. A opção que o conjunto dessas políticas revela é a escolha pela integração social dos segmentos até então excluídos do mercado e da sociedade via consumo. E portanto, a prioridade de sua integração via políticas distributivas sem no entanto atacar a essência da desigualdade socioeconômica por meio de políticas redistributivas dos ativos econômicos.

De fato, a par o impacto das políticas adotadas na queda da desigualdade social no país, ele foi muito mais acentuado 
na diminuição da pobreza e da miséria dos extremamente pobres, promovendo inclusão social por meio de acesso a renda, seja via salário-mínimo e seu efeito cascata sobre os benefícios previdenciários, seja via política de transferência de renda. Os programas sociais de combate à pobreza acompanham o avanço das políticas sociais atinentes aos direitos constitucionais. $\mathrm{O}$ eixo estruturante do conjunto desses programas é o Programa Bolsa Família, criado em outubro de 2003. O objetivo consistia em se estruturar um programa de transferência condicionada de renda que utilizasse um único cadastro, unificando os programas oriundos dos governos FHC, e que servisse progressivamente como instrumento de gestão para todos os setores da área social. Mais que isso: do ponto de vista da gestão da coisa pública, a proposta original consistia em que as condicionalidades nas áreas da saúde e educação não servissem essencialmente como instrumentos de penalização dos "inadimplentes" com 148 suas obrigações, mas que esses não cumprimentos das obrigatoriedades se transformassem em parâmetros de monitoramento das políticas públicas locais, não recaindo imediatamente a "culpa" sobre o beneficiário e a penalidade de seu benefício cortado.

A equipe de governo tinha claro que: 1) o PBF consistia num programa de combate imediato à pobreza; 2) que mecanismos mais consequentes de inclusão social dos pobres e miseráveis dependem de políticas econômicas de criação de emprego e postos de trabalho; 3) que a transparência dos procedimentos na concessão das bolsas era fundamental para sua credibilidade junto à população e como instrumento de quebra dos tradicionais traços clientelistas e assistencialistas que historicamente permeiam a área social. Do ponto de vista econômico, o PBF significou e vem significando um impacto econômico nas áreas mais pobres do país porque monetarizou a economia local. Mas, mais que isto, possibilitou que os segmentos excluídos da sociedade e do 
mercado passassem a vivenciar duas experiências até então por eles desconhecidas: a da autonomia enquanto sujeitos sociais, e em decorrência o sentimento de auto estima, e a possibilidade de terem um projeto de futuro, sobretudo para seus filhos. Expressiva a frase de uma carta de uma candidata ao benefício do PBF ao Presidente Lula, porque expressa de forma condensada a consciência da realidade em que vive e das suas possibilidades como alguém que valoriza a presença de um projeto futuro: "Senhor Presidente uma ajuda ela se acaba; o que necessito é de um emprego que garanta minha vida, sem que eu possa estender a mão e pedir esmola" (Cohn, 2012, p. 61). Ou, segundo pesquisa de Walquíria Leão Rego e Alessandro Pinzani (Rego e Pinzani, 2013, p. 120) os depoimentos de mulheres vivendo nos rincões do Nordeste e que expressam a conquista da sua autonomia quando recebem o benefício: "porque a gente tem mais liberdade no dinheiro". Com ritmo rápido de crescimento, o programa cobre atualmente quase 14 milhões de famílias, compromete menos de $0,5 \%$ do PIB, tem baixíssimo custo de administração, e inova ao retirar do poder local a discricionariedade da concessão das bolsas, já que o cadastro realizado no nível local passa por verificação de consistência dos dados realizada pelo nível central. Mas o Bolsa Família não se configura como um direito social, como os benefícios previdenciários e de assistência social, embora se configure como um "quase direito" dada a forma como se enraizou na sociedade, e como foi implantado pela gestão federal dos vários governos de 2003 até 2016, tendo como horizonte a implantação da Renda Básica de Cidadania aprovada pela Presidência da República em 2004. Não por acaso a secretaria responsável pelo PBF no interior do antigo MDS foi denominada de Secretaria Nacional de Renda de Cidadania (Senarc), já que o programa era entendido como um primeiro passo para a implantação da renda de cidadania. 
$\mathrm{O} \mathrm{PBF}$, que dentre as políticas e programas sociais assumiu o palco, até pela sua capacidade potencial de articulação dos demais programas e políticas sociais, associa-se a estes, redundando numa rede de proteção social composta por atendimento aos direitos sociais constitucionais em construção de outros benefícios e serviços que contemplam também demandas sociais, sobretudo da base da pirâmide social, embora não configurados como direitos, mas que no conjunto significam a inclusão social dos estruturalmente excluídos via consumo, vale dizer, via integração no mercado. Isto, associado à "uberização" do trabalho, aponta para a baixa resistência da sociedade frente à desconstrução e o desmonte dessa rede, uma vez que "a burocracia estatal, viúva da administração de sucessivos governos e regimes políticos, acabe convertendo-se num imenso cemitério de projetos políticos" (Oszlack, 2012 apud Spinelli, 2012, p. 124). Noutros termos, sem resistência do aparato estatal que esses 150 projetos políticos, que trazem consigo seu leque de políticas sociais, acabem se transformando em projetos de governo, sem possibilidade de se sedimentarem e se enraizarem na sociedade. E assim serem desmontados a cada governo que assume o poder. Neste quesito ressalta uma dimensão do conteúdo social das políticas governamentais em geral, e das sociais em particular, e que diz respeito ao sentido de eficácia social que nelas se imprime, a depender da orientação política e das forças políticas que os governos expressam.

Eficácia social significa aqui o conteúdo social que a gestão das políticas públicas imprime às suas ações. Basicamente, tomando dois extremos, a da dominação - políticas restritivas e punitivas (descumprimento das condicionalidades do PBF levando à suspensão imediata da concessão dos benefícios, por exemplo) - ou o da autonomia dos sujeitos sociais (utilização do cumprimento ou não das condicionalidades do PBF como parâmetro de monitoramento da gestão das políticas públicas, não culpabilizando de forma imediata 
o beneficiário e excluindo-o do programa, por exemplo). E, claro que a opção pelo conteúdo social da autonomia e não reprodução da dominação dos sujeitos sociais, sobretudo os pobres, tende a gerar conflitos entre a lógica estatal da administração pública e a lógica da obediência aos princípios de políticas sociais autonomistas, que não respondem necessariamente à racionalidade do custo/efetividade estrito senso, tão ao gosto do ideário neoliberal.

\section{As políticas de abate social a partir de 2016: da desconstrução à destruição}

A cassação do mandato da presidente Dilma Rousseff significa, para a área social, a quebra do projeto de inclusão social e de políticas de combate à fome que vinha sendo desenvolvido desde 2002, e que redundou na saída do Brasil do Mapa da Fome, na declaração do país como livre da poliomielite e do sarampo. No entanto, o distanciamento da presidente Dilma dos movimentos e segmentos organizados da sociedade, associado à opção econômica de seu segundo governo contrária ao prometido em campanha, enfraquecem a base social de sustentação do arcabouço institucional da rede de proteção social que vinha sendo implantada e desenvolvida. Com isso, a burocracia estatal rapidamente, sob regência dos novos "donos do poder", reverte o sentido das políticas sociais, que de inclusivas, passam a ser excludentes e abertamente residuais, pautadas pelo mínimo social.

A partir de então encerra-se o que Fagnani (2017) denomina de "o breve ciclo da cidadania social no Brasil". Aponta o autor que

A regressão da cidadania social, em curso, é o desfecho do longo processo de reação contra as conquistas dos movimentos sociais dos anos de 1970 e 1980. A Constituição de 1988, desaguadouro daquele processo, inaugurou uma etapa inédita de construção da cidadania, desenhando-se 
um sistema de proteção social inspirado em alguns valores do Estado de Bem-Estar Social: universalidade (em contraposição à focalização); seguridade social (em contraposição ao seguro social); e direito (em contraposição ao assistencialismo). (Fagnani, 2017, p. 2)

O resgate dessa citação vem a propósito de assinalar que os preceitos constitucionais desde a sua origem contaram com a oposição das elites econômicas e políticas do país no que diz respeito aos direitos sociais e à construção de um Estado de Bem-Estar Social. Processo que, a partir de 1995, com suas nuances marcadamente distintas, possibilitou, em que pesem as reações contrárias, avanços na construção desse Estado. Sempre, no entanto, tramados pelos fios da tensão entre projetos políticos pautados pelo ideário de um Estado Mínimo ou de um Estado Social.

Em 2016 essa tensão entre projetos de nação e de país 152 em disputa tem um round decisivo, formalmente sem ruptura das instituições democráticas, e as elites brasileiras abrem um novo ciclo em que

o arcaico voltou a dar as caras sem pudor, desta vez como sócio menor de uma coalização política, financeira e empresarial que, ao perder as eleições [em 2014], resolveu assumir o controle do governo pela via do golpe. A utopia pode ter eclipsado a realidade, tão cristalinamente clara, de que a democracia e a cidadania social são corpos absolutamente estranhos ao capitalismo brasileiro. (Fagnani, 2017, p. 17)

No período de 2016 a 2018 não se pode interpretar como tendo havido a destruição do arcabouço da rede de proteção social no país. Apesar dos golpes contundentes que sofreu, tais como a EC 95/2016 que cria o teto de crescimento das despesas na área social vinculado à inflação, 
do aumento do percentual da Desvinculação de Receitas da União (DRU) de 20 para 30\%, da reforma trabalhista, e da ameaça da reforma previdenciária, que só ocorreria em 2019. Esse período caracteriza-se não pela destruição propriamente dita do arcabouço social que vinha sendo construído e consolidado, mas pela sua desconstrução. $\mathrm{O}$ discurso que fundamenta as reformas não é agressivo; elas são justificadas como forma de enfrentamento do desajuste fiscal, propondo-se a desconstitucionalização dos direitos sociais. $\mathrm{O}$ traço maquiavélico que marca esse período de transição entre 2016 e o pesadelo que se inicia em 2019 para a área social é que o formato das políticas e programas sociais continuaram como tais, embora progressivamente desidratados e tendo pervertidos seu conteúdo social até então vigente. A racionalidade técnica passa a estar a serviço dos interesses econômicos da administração pública, e contra os interesses dos cidadãos, mas em nome da defesa destes. Acena-se, então, mais do que nunca, com as vantagens do mercado frente à irracionalidade e falta de capacidade de gestão do Estado; mercado este que, tal como nas origens de sua presença na área social, caracteriza-se por se constituir num mercado sem risco, porque tem no Estado a garantia da sua demanda. Asfixia-se a área social com o congelamento de recursos para seu financiamento, e promove-se o empreendedorismo individual como substituto do trabalho com estabilidade. Esvazia-se o SUS com restrição de recursos e de contratação de pessoal e enxugamento de programas, porém seu arcabouço institucional continua o mesmo, utilizando-se a tática de um ninho vazio. Tem início na área social a privatização da gestão dos serviços sociais por meio da aceleração de contratações de instituições públicas de direito privado, que significam a privatização da gestão pública estatal pela racionalidade privada.

A partir de 2019 o jogo endurece. Inicia-se um processo de destruição truculenta do arcabouço social da 
rede de proteção social, mas não só: do meio ambiente, do direito à terra por parte dos trabalhadores rurais, indígenas e ribeirinhos, dos direitos dos negros, dos LBGTQI+, enfim, de todos os direitos que não respondam à bíblia dos novos donos do poder. $\mathrm{O}$ pacto de solidariedade social que até então vinha sendo construído a duras penas e crivado de tensões vem agora sendo substituído a ferro e fogo (literalmente) pela norma régia de cada um por si e contra os outros. A burocracia estatal se torna o algoz e o cemitério das políticas sociais e das práticas de gestão inovadoras e progressistas da área social.

O vaticínio e o propósito do atual chefe de Estado vêm sendo cumpridos à risca: "há muita coisa a ser destruída para depois construir" (construir o quê, não se sabe). O objetivo é retornar aos anos 1950, e particularmente aos anos 1960. Mas numa situação agravada uma vez que está se tratando de romper qualquer forma de solidariedade social, mesmo 154 aquela neoliberal de focalização das políticas sociais aos segmentos extremamente pobres da população. Não se trata mais de propostas de focalização versus universalização das políticas e dos programas sociais, mas de destruição de todo aparato social, começando por mudar o conteúdo social desses programas e políticas. Os pobres foram excluídos da agenda pública. Tome-se como exemplo a operação "pente fino" na previdência e assistência social, e no PBF. Voltam as filas de espera para a concessão dos benefícios (3,5 milhões de famílias no caso do PBF), os prazos para respostas de pedidos são indeterminados, entre 2015 e 2019 - a população dos moradores de rua na cidade de São Paulo aumentou em $53 \%$, atualmente 11,7 mil dormindo em abrigos e 12,6 mil nas ruas (PMSP, 2020) - ; 1,7 milhões de segurados da previdência social aguardam retorno após entrada do pedido de concessão de benefício, inclusive gestantes. O Brasil volta para o Mapa da Fome; o sarampo ressurge a começar pelos estados mais ricos do país; a sífilis por transmissão vertical 
volta a se fazer presente de forma expressiva; a culpabilização dos indivíduos por suas doenças é uma constante. Da mesma forma a culpabilização dos pobres por terem ousado começar a ocupar o mesmo espaço dos não pobres, seja em aeroportos, Miami, ou nas universidades.

O conjunto de ações do atual governo a partir de 2019 é marcado pela aporofobia, e sua tradução, por ações que penalizam sobretudo os mais pobres, seja por meio de restrição eivada de arbitrariedades de acesso ao BPC, seja por destruir a credibilidade do PBF quanto a critérios de distribuição das bolsas, como recentemente, quando as novas bolsas foram destinadas em 3\% para o Nordeste e 76\% para o Sul/Sudeste, sendo que aquela região apresenta $36 \%$ dos pobres e extremamente vulneráveis do país. Agrega-se a esse enxugamento dos benefícios distributivos sem vínculo contributivo à reforma da previdência social, tida como carro chefe do caminho para a retomada do crescimento. Aprovada e homologada, ela destitui direitos, acompanhando a destituição de direitos promovida pela reforma trabalhista, proíbe acúmulo de benefícios (pensão por viuvez e aposentadoria, por exemplo), acaba com a atualização do valor dos benefícios, além de aumentar idade e tempo de contribuição e diminuir o valor dos benefícios. Este é o resultado na lei de algo que já vem ocorrendo em nome da racionalidade e corte de distorções na concessão de benefícios: agentes da previdência social vem recebendo pagamento de bônus proporcional ao corte de direitos, via perícia, junto ao INSS. Cortes brutais vem sendo igualmente feitos no PBF. Essa perversidade não reside somente numa pretensa necessidade de se imprimir uma "racionalidade custo/efetividade" às ações do Estado. Ela consiste num projeto político e social de destituição material e ideológica dos assalariados e dos pobres em termos de seus direitos, portanto, enquanto sujeitos sociais. É historicamente conhecido por estudiosos da área que uma vez expulsos de um sistema 
da área social, dificilmente se retorna a ele, e quando se consegue, o período até o retorno é imenso. Daí a importância do conteúdo social dos programas, independentemente das suas normas formais: por exemplo, no conflito entre a lógica do conteúdo social das políticas públicas e a lógica estatal da administração pública, no caso do PBF até 2016 o cuidado é para que não fossem feitos desligamentos do Programa de forma automática e imediata, sempre buscando dar novas oportunidades para os cidadãos esclarecerem as lacunas ou faltas registradas pelo "sistema". Sempre em obediência às regras da administração pública.

Se a destruição de todas as políticas do arcabouço institucional de proteção social e de garantia dos direitos sociais básicos, que atinge também as áreas da cultura, ciência e tecnologia, meio ambiente, e todo o rastilho do que diz respeito a garantias de vida digna, a previdência social é aquela que mais atinge o núcleo das políticas distributivas pelo seu caráter efetivamente redistributivo: segundo a Associação Nacional de Auditores Fiscais, em 2017 em 88\% dos municípios brasileiros a transferência monetária da previdência e da assistência social era maior que as suas receitas tributárias; e em 73,6\% dos municípios entre 10 e 20 mil habitantes ela era maior que a transferência da União por meio do FPM (França, 2019). Lena Lavinas (2019) mostra como em 2018 o índice de Gini na faixa entre 14-59 anos era de 0,59 enquanto entre aposentados e pensionistas com mais de 60 anos era de 0,39, a menor medida de desigualdade da histórica brasileira. E um último adendo: o modelo da reforma é o chileno, reconhecidamente fracassado em termos de suas funções sociais de proteção social. No Chile atual, 8 entre 10 aposentados pela previdência social recebem benefício inferior a um salário-mínimo, e 44\% dos aposentados estão abaixo da linha da pobreza. Mas o sistema previdenciário chileno, nosso modelo, é reconhecidamente bem sucedido 
em termos de política econômica: as Administradoras de Fundos de Pensão movimentam $70 \%$ do PIB chileno.

Essa destruição da rede de proteção social e dos direitos fundamentais dos cidadãos significa a quebra dos pactos de solidariedade social e do ciclo de cidadania social que se instaurou a partir de 1988, e implica a quebra da expectativa de direitos, portanto, a quebra da possibilidade de projetos de futuro por parte de largos setores da sociedade. Abre-se um novo ciclo sinistro: se no Brasil paradoxalmente a expansão dos direitos contributivos deu-se em períodos de regimes autoritários (cidadania regulada); se entre 1995-2002, no período FHC, ocorreu a expansão fracionada de benefícios sociais como não direitos; se de 2003 a 2010, no período Lula, ocorreu uma expansão agressiva das políticas sociais e da implementação dos direitos sociais (e dos "quase direitos", no caso do PBF) com incentivo da participação social; se de 2011 a 2016, no período Dilma, ocorreram a consolidação das políticas e programas sociais e a instituição do Sistema Nacional de Participação Social em 2014, embora no segundo mandato da presidente tenha havido um distanciamento do governo com relação à sociedade; se entre os anos de 2016 e 2018 assiste-se à desconstrução do aparato social até então construído, no período que se inaugura com Bolsonaro tem início a destruição de toda e qualquer política de proteção social no país.

Bebendo na máxima absolutista do l'État c'est moi, sem ser capaz de alcançar essa sutileza, promove-se a despolitização da sociedade e a criminalização da ação política, evangeliza-se a violência. Inaugura-se uma nova era, em que o novo consiste na destruição dos direitos sociais num contexto formalmente democrático. O que nos leva a buscar aprender com o passado tanto sobre a capacidade da via pelo "reformismo fraco" e pela "transformação pelo alto" (Singer, 2018) e a opção pela inclusão social pelo consumo descurando-se da politização dos beneficiários 
dessas políticas, quanto deslindar as consequências do golpe pós-moderno sustentado pelo velho atraso brasileiro, como aponta Bernardo Ricupero (Ricupero, 2015). E por fim, perseguir respostas para a indagação de Wanderley Guilherme dos Santos: os meandros pelos quais "a democracia [no Brasil] perdeu o pudor de não ser democrática" (Santos, 2017). Certamente, um dos fatores é a combinação, no âmbito das relações sociais, do moderno com o atraso num contexto em que o predomínio da condição de trabalhador (sobretudo dentre os pobres) ocorre marcada pela instabilidade, intermitência, insegurança e, portanto, sem possibilidade de qualquer projeto de futuro, que em grande parte era possibilitado pela rede de proteção social que está sendo destruída.

\section{Amélia Cohn}

é socióloga; docente do Programa de Pós-Graduação 158 em Direito da Saúde Dimensões Individuais e Coletivas, da Universidade Santa Cecília (Unisanta). Professora aposentada da Faculdade de Medicina da Universidade de São Paulo. Foi pesquisadora e presidente do Centro de Estudos de Cultura Contemporânea (Cedec); relatora do Documento Oficial Brasileiro para a Cúpula de Desenvolvimento Social da ONU de 1995; membro da primeira equipe do Programa Bolsa Família, primeiro governo. Autora, dentre outros, de Cartas ao Presidente Lula - Bolsa Família e direitos sociais (Azougue Editorial, 2012).

\section{Bibliografia}

ALSTON, Lee; MOLO, Marcus A.; MUELLER, Bernardo; PEREIRA, Carlos. 2013. Changing social contracts: beliefs and dissipative inclusion in Brazil. Journal of Comparative Economics, n. 41, pp. 48-65. AVRITZER, Leonardo. 2002. O orçamento participativo: as experiências de Porto Alegre e Belo Horizonte. In: DAGNINO, Evelina (org.). 2013. Sociedade civil e espaços públicos no Brasil. São Paulo: Paz e Terra. pp. 17-45. 
BARBOSA, Bernardo. 2019. Bolsonaro ironiza críticas sobre desmatamento: 'sou o capitão motosserra”. UOL Notícias, 21 ago. 2019. Disponível em: https://bit.ly/2V5xr87. Acesso em: 4 nov. 2019.

BARBOSA, Nelson; PEREIRA DE SOUZA, José Antonio. 2010. A inflexão do governo Lula: política econômica, crescimento e distribuição de renda. In: SADER, Emir; GARCIA, Marco Aurélio (org.). Brasil entre o futuro e o passado. São Paulo: Boitempo. pp. 65-75.

BOLSONARO: "quilombola não serve nem para procriar". 2017. Congresso em Foco, 5 abr. Disponível em: https://bit.ly/2V6IG0b. Acesso em: 4 nov. 2019. CAILLÉ, Alain. 2014. Dádiva, care e saúde. Sociologias, v. 16, n. 36, pp. 42-59. COHN, Amélia. 1999. As políticas sociais no governo FHC. Tempo Social, v. 11, n. 2, pp. 183-197.

COHN, Amélia. 2012. Cartas ao Presidente Lula: Bolsa Família e direitos sociais. Rio de Janeiro: Azougue.

CONFERENCIA: 'Democracia: Qual futuro?'. 2016. Youtube. 1 vídeo (5 min). Disponível em: https://bit.ly/2A6bMVp. Acesso em: 14 abr. 2020.

CORDATO, Adriano N. 1996. Sistema Decisório e Ditadura Militar: uma análise do governo Geisel. Paper apresentado no XX Encontro Anual da Anpocs, Caxambu, 22 a 26 de outubro.

CORTINA, Adela. 2017. Aporofobia, el rechazo del pobre. Barcelona: Paidós.

FAGNANI, Eduardo. 2017. O fim do breve ciclo da cidadania social no Brasil (1988-2015). Campinas: Unicamp. (Texto para discussão, n. 308).

FERREIRA DE SOUZA, Pedro H. C. 2018. Uma história da desigualdade: a concentração de renda entre os ricos no Brasil 1926-2013. São Paulo. Hucitec.

FOOT HARDMAN, Francisco. 2019. "O desgoverno Bolsonaro e o Estado de Mal-Estar: desafio à resistência e luta das esquerdas”. In: GALLEGO, Esther Solano (org.). 2019. Brasil em Colapso. São Paulo: Editora Unifesp. pp. 121-134.

FRANÇA, Álvaro de S. 30 abr. 2019. A previdência social e a economia dos municípios. Anfip. Disponível em: https://bit.ly/3ek9kdq. Acesso em: 14 abr. 2020.

"IDEOLOGIA de gênero é coisa do capeta". 10 ago. 2019. diz Bolsonaro a evangélicos. Carta Capital. Disponível em: https://bit.ly/2VsNbkn. Acesso em: 4 nov. 2019.

LAVINAS, Lena. 2019. A quem a Reforma da Previdência privilegia? Cebes, 10 mar. Disponível em: https://bit.ly/3clGYxN. Acesso em: 14 abr. 2020. LAPAQUE, Sebastién. 4 set. 2016. Eduardo Galeano, a voz da fraternidade. Le monde diplomatique Brasil. Disponível em: https:/ / bit.ly/2wDzGWO. Acessado em 14 abr. 2020. 
MAIA, Gustavo. 2019. 'Os caras vão morrer na rua igual barata, pô', diz Bolsonaro sobre criminosos. G1. Disponível em: https://glo.bo/2Vp61ZU. Acesso em: 14 abr. 2020.

MEDEIROS, Marcelo. 2016. Meio século de desigualdades no Brasil. Revista Brasileira de Ciências Sociais, v. 31, n. 90, pp. 175-177.

PUTTI, Alexandre. 19 ago. 2019 Bolsonaro: "enquanto eu for presidente, não tem demarcação de terra indígena”. Carta Capital. Disponível em: https://bit.ly/2xidfXL. Acesso em: 14 abr. 2019.

REGO, Walquíria L.; PINZANI, Alessandro. 2013. Vozes do Bolsa Família: autonomia, dinheiro e cidadania. São Paulo: Editora Unesp.

RESTREPO, Luis Alberto. 1997. "La participación ciudadana: participación tutelada o participación abierta?". In: LODOÑO, Luis Fernando et al. Sociedad civil, control social y democracia participativa. Bogotá: Tercer Mundo. pp. 27-38.

RICUPERO, Bernardo. 2018. Seminário CEDEC/USP. 8/08/2015. In SINGER, André. O Lulismo em Crise - Um quebra-cabeşa do Período Dilma (2011-2016). São Paulo: Cia das Letras. pp. 15-16.

SANTOS, Wanderley G. 1979. Cidadania e justiça: a política social na ordem brasileira. Rio de Janeiro: Campus.

SANTOS, Wanderley G. 2017. A democracia impedida: o Brasil no século XXI. 160 Rio de Janeiro: Editora FGV.

SÃO PAULO (Município). 2020. Censo da população em situação de rua. Disponível em: www.capital.sp.gov.br/noticia/prefeitura-de-sao-paulo. Acesso em: 31 jan. 2020.

SINGER, André. 2018. O Lulismo em crise: um quebra-cabeça do período Dilma (2011-2016). São Paulo: Companhia das Letras.

SOUZA, Jessé. 2003. "(Não) Reconhecimento e subcidadania, ou o que é "ser gente"? Lua Nova, n. 59, pp. 51-74.

SOUZA, Jessé. 2017. A elite do atraso: da escravidão à Lava Jato. Rio de Janeiro: Leya.

SPINELLI, Hugo. 2012. El proyecto político y las capacidades de gobierno. Salud Colectiva, v. 8, n. 2, pp. 107-130 


\section{AS POLÍTICAS DE ABATE SOCIAL NO BRASIL CONTEMPORÂNEO}

AMÉLIA COHN

RESUMO: O artigo percorre as trajetórias da construção e da desconstrução da rede de proteção social no Brasil até 2020. O objetivo é ressaltar os traços históricos desse processo, com ênfase no período pós-constituição de 1988, e como se avançou, até 2016, na construção de um arcabouço institucional inspirado num modelo de Estado de Bem-Estar Social. A partir de 2016 analisa-se a desconstrução desse arcabouço, e a partir de 2019 a sua destruição. As transições sem rupturas, seja entre regimes políticos, seja entre governos, deixaram suas marcas, onde conciliações e enfraquecimento dos laços do Estado com a sociedade apontam para a insuficiência dos projetos políticos com forte conteúdo social experimentados no pós 1988, sobretudo a partir deste século, para a resistência da garantia na atualidade dos direitos sociais conquistados.

PALAVRAS Chave: Destruição dos Direitos Sociais; Direitos Sociais e Inclusão Social; Políticas Sociais de Inclusão e de Exclusão social.

\section{ABOUT THE POLICIES OF SOCIAL SLAUGHTER IN CONTEMPORARY BRAZIL}

ABSTRACT: The article revisits the trajectories of both the building and the deconstruction of the Social Protection Network in Brazil until 2020. Its goal is to retrace the historical trends of the process, emphasizing the period prior to the 1988 Constitution, and how it advanced, up to 2016, in the construction of an institutional framework that was inspired in a Social Welfare State. Following this period, the article analyses the liquidation of this very framework and, from 2019 on, its destruction. Transitions which 
were defined as not bringing actual ruptures, be those on political regimes or between governments, are shown to have left their marks, by which conciliations and the weakening of ties between the State and civil society point out to the insufficiency of political projects that would have strong social content and which were experienced after 1988. This trend is even stronger during this century, and this insufficiency influences the capacity of resistance and maintenance of guarantees for keeping the conquered rights as established from their emergence and the struggle that founded them.

Keywords: Social Rights Liquidation; Social Rights and Social Inclusion; Social Policies; Social Inclusion and Exclusion.

Recebido: 13/02/2020 Aprovado: 30/03/2020 